7 Haussler, M. R., Boyce, D. W., Littledike, E. T., and Rasmussen, H., Proc. US Nat. Acad. Sci., 68, 177 (1971).

${ }^{8}$ Norman, A. W., Myrtle, J. F., Midgett, R. J., Nowicki, H. G., Williams, V., and Popják, G., Science, 173, 51 (1971).

9 Urban, E., and Schedl, H. P., Amer. J. Physiol., 219, 944 (1970).

10 Harrison, H. E., and Harrison, H. C., Amer. J. Physiol., 199, $265(1960)$

11 Martin, D. L., and DeLuca, H. F., Arch. Biochem. Biophys., 134, 139 (1969)

12 Schachter, D., Kimberg, D. V., and Schenker, H., Amer. J. Physiol., 200, 1263 (1961).

13 Wasserman, R. H., and Taylor, A. N., in Mineral Metabolism (edit. by Comar, C. L., and Bronner, F.), 3, 321 (Academic Press, New York and London, 1969).

14 Papworth, D. G., and Patrick, G., J. Physiol., 210, 999 (1970).

15 Martin, D. L., Melancon, M. J., and DeLuca, H. F., Biochem. Biophys. Res. Comm., 35, 819 (1969).

16 Haussler, M. R., Nagode, L. A., and Rasmussen, H., Nature, 228, 1199 (1970).

17 Holdsworth, E. S., J. Membrane Biol., 3, 43 (1970).

18 Adams, T. H., and Norman, A. W., J. Biol. Chem., 245, 4421 (1970).

19 Hurwitz, S., and Bar, A., Amer. J. Physiol., 222, 761 (1972).

20 Wasserman, R. H., J. Nutr., 77, 69 (1962).

21 Norman, A. W., Amer. J. Physiol., 211, 829 (1966).

22 Lawson, D. E. M., Wilson, P. W., and Kodicek, E., Biochem. J., 115,269 (1969).

${ }^{23}$ Patrick, G., and Stirling, C., Int. J. Appl. Radiat. Isotopes, 22, 627 (1971)

\section{Subcutaneous Growth of Human Tumours in Mice}

CASTRO $^{1}$ reported the successful growth of human tumours in immune suppressed mice after the tumour tissue had been implanted beneath the left kidney capsule. In similar work we have used the subcutaneous route because we found this to be the most successful in our extensive investigations into tumour growth in ALS treated mice.

Female CBA mice were thymectomized at 4 weeks, whole body irradiated ( $900 \mathrm{R}), 2$ weeks later and reconstituted within $3-4 \mathrm{~h}$ of irradiation, using $1 \times 10^{7}$ syngeneic bone marrow cells, given i.v.

Table 1 Subcutaneous Tumour Growth

\begin{tabular}{|c|c|c|c|c|c|}
\hline \multirow[b]{2}{*}{ Tumour type } & \multicolumn{5}{|c|}{ Percentage survival of tumours } \\
\hline & $1 \mathrm{wk}$ & $2 \mathrm{wk}$ & $3 \mathrm{wk}$ & $4 \mathrm{wk}$ & $5 \mathrm{wk}$ \\
\hline HeLa & 100 & 100 & 100 & 53 & 21 \\
\hline Colon & 100 & 100 & 100 & 80 & \\
\hline Stomach & 100 & 100 & 50 & 38 & 38 \\
\hline Hep 2 & 75 & 75 & 50 & 50 & 12 \\
\hline Rectum & 100 & 75 & 50 & 50 & \\
\hline Caecum & 100 & 100 & 50 & 50 & 25 \\
\hline Breast adenocarcinoma & 0 & 0 & 0 & 0 & 0 \\
\hline $\begin{array}{l}\text { Secondary tumour, the } \\
\text { primary being in the breast }\end{array}$ & 70 & 70 & 70 & 70 & \\
\hline Lymph node from melanoma & 100 & 100 & & & \\
\hline
\end{tabular}

The tumours were obtained at operation and transported to the laboratory in Eagles minimal essential medium, containing $2 \%$ calf serum, 200 units of penicillin, and $100 \mathrm{mg}$ streptomycin. Tumour pieces of about $2 \mathrm{~mm}$ were implanted subcutaneously in a ventro/lateral site over the right hip joint. In our ALS experiments we found by experience that this was the most suitable site for implantation, in view of the large tumour growths obtained, often in excess of $2-3 \mathrm{~cm}$. In our present investigations we are able to report colonic tumour growths of the order of $12 \mathrm{~mm}$ within eleven days of implantation. This was assessed by direct palpation. Tumour types investigated are given in Table 1.

Our results clearly show that the subcutaneous route pro- duces good tumour growth which is easy to assess by direct palpation and therefore affords a means of judging the effectiveness of treatmeat without having to kill the mice. We feel this method will be useful for further in vivo investigations of human tumours.

We thank New End Hospital and Hampstead General Hospital for the supply of some of the tumours.

\section{R. FRANKS \\ F. T. Perkins \\ J. THORNTON HOLMES}

National Institute of Biological Standards and Control, Holly Hill, London NW3 $6 R B$

Received November 16; 1972; revised January 15, 1973.

${ }^{1}$ Castro, J. E., Nature, 239, 83 (1972).

\section{Inhibition of Pupariation in Sarcophaga bullata}

THE classical test used as the bioassay for the insect moulting hormone, ecdysone, is based on the failure of the posterior part of ligatured larvae of Calliphora erythrocephala (or other fly species) to tan unless an adequate dose of ecdysone is administered. It is crucial for the success of the test to select larvae at the right stage of development, and as closely as possible to the critical time for pupariation ${ }^{1}$. Larvae ligatured before the critical stage of natural ecdysone release may eventually pupariate in the front part where the hormone originates, but will never do so in the hind part. Post-critically ligatured larvae have had sufficient ecdysone released into the haemolymph previous to ligature to induce tanning in the hind parts. It is evident that at this time the anterior parts must also be post-critical. In larvae ligatured at this stage the anterior parts usually contract to the puparium and tan whereas the posterior parts merely tan without change in shape. The occurrence of tanning in the posterior part alone is therefore a paradox. Fraenkel ${ }^{2}$ along with the description of the "Calliphora assay" also reported that ligatured larvae occasionally tanned only in the posterior region. Several investigators have been subsequently surprised by this phenomenon of "anterior inhibition", but there has been no agreement as to its cause.

Kaplanis et al. ${ }^{3}$ observed anterior inhibition in the larvae of Musca domestica. Langley $^{4}$ attributed anterior inhibition in the larvae of Glossina morsitans to an inhibitory influence of the central nervous system which in a ligatured larva is confined to the anterior part. In contrast, Price ${ }^{5}$ hypothesized the presence of an inhibitory factor of the phenol oxidase inhibitor type, to account for a temporary inhibition of pupariation in the anterior parts of $C$. erythrocephala larvae ligatured between segments 8 and 9 . Fraenkel and Zdarek ${ }^{1}$ reported that in different species of flies the percentase of anterior inhibition is different. In the study reported here, with Sarcophaga bullata, it varied, according to the condition of the experiment, between 0 and $80 \%$. Chang ${ }^{6}$ observed a $96.9 \%$ anterior inhibition in Lespesia archippivora that had been in his view ligatured "pre-critically", and suggested that, contrary to common notions, ecdysone was produced in the posterior parts only. The injection of ecdysone into such anterior parts did not, however, induce tanning. In the absence of evidence about the pre-critical nature of his larvae we suggest that they were indeed ligatured post-critically and showed the same effect of anterior inhibition observed in the other species.

Our studies now confirm Fraenkel's original view ${ }^{2}$ that the inhibition of pupariation in post-critically ligatured larvae was 